\title{
The site occupancy assessment in tourmaline-supergroup minerals based on bond-length constraints
}

\author{
PETER BAČÍK ${ }^{1}$ AND JANA FRIDRICHOVÁ ${ }^{1}$
}

${ }^{1}$ Department of Mineralogy and Petrology, Faculty of Natural Sciences, Comenius University in Bratislava, Ilkovičova 6, Mlynská dolina, SK-842 15 Bratislava,

Slovakia, peter.bacik@uniba.sk

Theoretical bond-length calculation from ideal bond valences for each ion and coordination can predict ion site preference in the structure. It revealed that $T$ site can freely accommodate $\mathrm{Si}^{4+}$ and $\mathrm{Be}^{2+} ; \mathrm{B}^{3+}$ and $\mathrm{Al}^{3+}$ substitution requires compression or expansion of $\mathrm{TO}_{4}$ tetrahedron, respectively. The $B$-site occupancy is strictly limited to $\mathrm{B}^{3+}$. Proper bond lengths for octahedral sites were calculated for $\mathrm{Al}^{3+}$ (Z-site preference), $\mathrm{Ti}^{4+}, \mathrm{Mn}^{3+}, \mathrm{Ga}^{3+}, \mathrm{V}^{3+}, \mathrm{Fe}^{3+}$ (mixed preference), $\mathrm{Mg}^{2+}, \mathrm{Fe}^{2+}, \mathrm{Li}^{+}, \mathrm{Mn}^{2+}, \mathrm{Ni}^{2+}, \mathrm{Zn}^{2+}, \mathrm{Cu}^{2+}, \mathrm{Sc}^{3+}$ and $\mathrm{Zr}^{4+}$ ( $Y$-site preference). Another group of cations including $\mathrm{U}^{4+}, \mathrm{Th}^{4+}, \mathrm{Y}^{3+}$ and lanthanoids from $\mathrm{Tb}^{3+}$ to $\mathrm{Lu}^{3+}$ and $\mathrm{Ce}^{4+}$ have significantly longer bonds than typical $Y$-O, but they form too short bonds for the $X$ site. Therefore, they probably prefer octahedron. The usual empirical bond length for the $X$ site is met with $\mathrm{Na}^{+}, \mathrm{Ca}^{2+}, \mathrm{Sr}^{2+}, \mathrm{Pb}^{2+}$ and lanthanoids from $\mathrm{La}^{3+}$ to $\mathrm{Gd}^{3+}$, while $\mathrm{K}^{+}, \mathrm{Rb}^{+}$and $\mathrm{Cs}^{+}$bond lengths are unbearably large for tourmaline $X$ site.

For every structural site, the "Goldilocks zone" of bond lengths can be assumed. This defines the range of bond length, which does not induce large structural tension and distortion. It is quite narrow in small sites such as $B$ and $T$ in tourmaline, but larger in sites with higher coordination number. This is the case of $\mathrm{Al}$ and $\mathrm{B}$ at $T$ site - they substitute for Si but only in a limited proportion. Similarly, the proportion of REE in tourmaline is limited, although these can be abundant in the environment. It results from the deviation from the "Goldilocks zone" for both $X$ and $Y$ site and also relatively high charge for the $X$ site. However, based on the present data, if present, REE likely partition between the $Y$ (HREE) and $X$ (LREE) site. However, the final tourmaline composition results from interaction of structure with the genetic environment. The proportion of REE in tourmaline is structurally limited, while e.g. $\mathrm{Zr}^{4+}, \mathrm{Sc}^{3+}, \mathrm{Sr}^{2+}$, $\mathrm{Pb}^{2+}$ have only geochemical limits with no obvious structural limit.

Acknowledgement: This work was supported by the Slovak Research and Development Agency under the Contract no. APVV-18-0065. 